\title{
Now you see it .....
}

\section{We have a responsibility to examine the evidence fairly rather than continue to reinforce our preconceptions and prejudices.}

\begin{abstract}
n this issue of the BDJ we are publishing a 'Personal View' titled Do we really want a quick fix? This report examines some of the claims made in certain articles, mainly in the controversial areas of orthodontics, orthopaedics and TMJ disorders. Rob Chate, the author, has presented an overview of the evidence to clarify the whole area as scientifically as possible.
\end{abstract}

This is a very pertinent time to be looking at this topic, especially in the wake of the television programme Dispatches which is currently the topic of some debate in our letters column. For me, the real importance and relevance of this Personal View is summarised in the conclusion on page 183 of this issue, especially the sentence "Yet, in those branches of science that deal with human welfare there really should be no such thing as giving the benefit of the doubt ...". While theorists can argue about the formation of the universe or debate the classification of plants without too much effect on the rest of us, when a dentist incorrectly selects a treatment option based on the anecdotal experience of others then a human being may suffer irreparable damage.

Perhaps the real problem is the belief that we have a God-given right to our own clinical opinion. In other words, if I truly believe that my diagnosis and treatment plan is right then no-one else can argue with it. This inevitably creates the dilemma that we need to ensure the public is protected from inappropriate behaviour (including clinical treatment) provided by all of us, while at the same time recognising there will inevitably be differences of opinion as to what appropriate behaviour is.

As with so many things it is all a question of balance. When does a genuine difference in clinical thinking become unreasonable? The answer, trotted out by some academic quarters, is to be 'evidence-based' in everything we do. But we all know that a great deal of clinical treatment lacks evidence at the moment, and this then can lead to the conclusion that evidence-based dentistry is a nuisance created by people who want to take away our freedom. Those taking this view tend to revert back to the anecdotal approach of believing that what seems to work must be best.

Alas, what people who take this approach fail to appreciate is the human ability to rationalise. Perception (the way we view the world and therefore assume to be reality) is a dangerous deceiver, focusing on the aspects that reinforce our current beliefs. We subconsciously filter out all things that disprove our current view, thereby reassuring ourselves that we were 'right all along. We do not even know we are doing it. That is why long held beliefs that we are 'right' are so dangerous. Yet, as thinking people, surely we must appreciate that other views, especially when supported by scientifically acceptable evidence, may also be right and we have a responsibility to examine the evidence fairly rather than continue to reinforce our preconceptions and prejudices. Sadly the Dispatches programme (along with many other examples) demonstrates the difficulty created for our patients when this does not occur.

All the above neatly brings me back to the paper in this $B D J$. As Rob Chate states so eloquently we must guard against the subtle persuasion used by those who have little evidence to back their claims, however attractive their claims appear when we first hear them, and however effective they may seem to be in our own hands. As caring professionals we have a real duty to examine evidence in a scientific and responsible way, knowing that our beliefs are influencing our perception and that the currently accepted reality may not fit in with our own ideas. After all, besides providing evidence we are 'growing up' it is also the only way we can truly care for our patients. 